\title{
Flow at Work, Work Satisfaction and Big Five Personality Traits among Slovenian Primary School Teachers
}

\author{
MAŠA TAVČAR \\ University of Primorska, Slovenia \\ masa.tavcar@gmail.com \\ ANA ARZENŠEK \\ University of Primorska, Slovenia \\ ana.arzensek@fm-kp.si
}

In this paper we assessed the connection between flow at work, work satisfaction and personality traits among 890 teachers from Slovenian public primary schools. We assumed flow at work was positively correlated to work satisfaction. Furthermore, flow at work was hypothesized to be positively correlated to extraversion and conscientiousness. Alternatively, flow at work was hypothesized to be negatively correlated to emotional stability. Three questionnaires: BAIJS, FLOW-W and 10-Item Personality Scale were applied. The main findings were that teachers who are satisfied with their work have repeatedly experienced a state of flow in their workplace. Likewise, state of flow has been more likely experienced by teachers with higher levels of extraversion, agreeableness, openness and conscientiousness. Teachers with low emotional stability have been less likely to experience flow at work as teachers with higher emotional stability. Implications of these findings are being discussed.

Key words: flow at work, work satisfaction, big five personality traits, primary school teachers, Slovenia https://doi.org/10.26493/1854-4231.14.151-163

\section{Theoretical Background}

Teachers' work is one of the more demanding professions. As their working lives are prolonged, it is important to investigate factors that are related to their job satisfaction, as this affects teachers' attitude to work and to students. Job satisfaction promotes well-being of teachers and, consequently, well-being of their students. Many factors relate to job satisfaction. In this article, we have focused primarily on flow at work, as it is one of the less researched psychological concepts in Slovenia. We also investigated how teachers' personality 
traits are related to flow at work and how they can, in conjunction with flow at work, encourage the creation of a better working atmosphere.

In this study we examined the importance of concepts of flow at work, personality traits and job satisfaction. We wanted to test the degree of correlation between flow at teachers' work and personality traits (namely extraversion, neuroticism and conscientiousness). We also tested whether teachers' flow at work was related to their job satisfaction.

\section{FLOW AT WORK}

The flow was first defined in 1975 by Mihaly Csikszentmihaly as an optimal experience where individual is fully involved in the present moment and in the current activity. Csikszentmihaly began to investigate flow while observing painters who persisted in painting, regardless of hunger, malaise and heat. Csikszentmihaly continued his research on a sample of chess players, mountaineers and dancers and found that intrinsic motivation was present in all and that the activity they performed was autotelic (Nakamura and Csikszentmihaly 2005). Intrinsic motivation involves participating in an activity solely because of one's own pleasure and satisfaction experienced during the task (Kopperud and Straume 2009). Autotelic activity is an activity that is rewarding in itself and enables individuals to visualize their goals and the effects of the activity (Branković, Hadžikadunić, and Mijanović 2017).

Flow at work is described as a subjective experience of being fully aware of one's skills and abilities, facing challenges in line with the abilities, obtaining feedback on one's work, and adjusting further behavior based on that information. During flow, one is deeply concentrated on the task, has a complete sense of control, and performs the task effortlessly (Fullagar, Delle Fave, and Van Krevelen 2017). People who experience flow often describe it as a condition of being one with the work task and fully committed to it. There is a clear awareness of the work goals, knowledge of the details that are important for the successful achievement of the goal. Flow at works is also characterized by distorted perception of time; while some people report faster passing of time, others report that during work activity the time stopped (Smolej Fritz and Avsec 2007). It is also important for the state of flow that one is freed from the 'inner voice' or 'inner critique' that is characterized by questioning oneself regarding expectations being or not being met or whether one's behavior conforms to social norms.

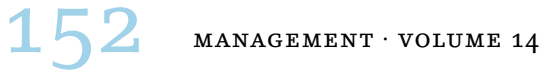


A state of flow is expected to occur when one is actively involved in a particular interaction with the environment, which may be physical, emotional or intellectual. Often, one experiences flow in various games and sports. It is important that one's abilities are aligned with the challenge. Low ability and challenge being too high cause anxiety. In case the challenge is not too demanding and the ability is high too, one gets bored. The unpretentious challenge and low abilities, however, cause the experience of apathy (Csikszentmihaly 2014). Apathy has been described as a negative and psychologically disturbing condition, accompanied by the perception of low challenges, lack of concentration and involvement, and limited mobilization of individuals' energy resources (Bassi and Delle Fave 2000; Delle Fave and Massimini 2005). Hence, there must be a match between skills and challenges in the work of teachers. If teachers have too few challenges, the principal must make sure that the challenge is upgraded to make the teacher's work more interesting. It is important that the principal is familiar with the type of task that motivates the teacher and encourages him or her to perform better. If the teacher is overworked and unable to reach the goal, it is the principal's job to reduce the challenge and provide sufficient support for that teacher. Three types of support exist, namely (1) emotional support to enhance the morale and to balance anxiety experienced by the teacher, (2) support with resources such as assigning an assistant and (3) providing additional training that enhances the teacher's abilities (Seemann and Seemann 2015).

The literature on circadian rhythms in humans suggests that the state of flow does not occur accidentally, but in the form of a curve or in a U-shape, where the tops represent beginnings and ends of the working day (Van Dongen and Dinges 2000). While studying surgeons, chess players and mountaineers, Csikszentimhaly also found that their state of flow did not occur during undemanding activities but during more difficult activities that expanded one's abilities and contained elements of novelty and the discovery of something new (Debus et al. 2014).

During flow, people exercise above-average abilities to accomplish above-average tasks. But flow is not only based on the characteristics of the task or activity, but also on the amount of personal and energy resources that a person is able to put into the task (Debus et al. 2014).

WORK SATISFACTION

Job satisfaction is a term that explains the degree to which one is satisfied with his or her work. Dimec et al. (2008) distinguish between 
(1) general job satisfaction, which is defined as the general attitude of the employee towards work and (2) satisfaction with individual aspects of the work situation, such as promotion options, satisfaction with one's coworkers, work tasks, resources, leadership, autonomy at work, work schedule etc.

There are several theories that attempt to define the concept of job satisfaction (Judge and Klinger 2008). The factors of job satisfaction can be classified into three categories: (1) situational theories that interpret job satisfaction as a consequence of the nature of work and other environmental aspects, (2) dispositional theories that place the source of satisfaction in the employee's personality characteristics. Furthermore, interactive theories (3) define job satisfaction as a consequence of specific situational factors and personality traits of an individual.

Demerouti (2006) claims that experiencing flow is driven by many factors, such as goal clarity, giving and receiving feedback, a sense of control, and a good balance between ability and challenge. Likewise, the core of motivational characteristics of work are the diversity of tasks, characteristics of work, autonomy, and receiving feedback (Demerouti 2006). These factors have also been proven to be predictors of job satisfaction. Although work satisfaction is a broader construct compared to flow, the factors contributing to the two are similar, so we conclude that they are related (Demerouti 2006). We claim that an individual who is satisfied with his or her work is more likely to experience flow at work (Straume 2004).

\section{BIG FIVE PERSONALITY TRAITS AND STATE OF FLOW}

The five-factor personality model covers five relatively stable personality dimensions: extraversion, neuroticism, agreeableness, openness and conscientiousness. Extraversion is characterized by a tendency to socialize with people; a person with a high degree of extraversion is predominantly eloquent, energetic and warm. Neuroticism (or low degree of emotional stability) encapsulates predominant emotional states of people; people with high levels of neuroticism tend to experience unpleasant emotions such as anxiety, anger, shame or guilt and can be distracted or stressed-out more easily than people with high levels of emotional stability. Openness describes an extent to which people are inclined to unconventional experience. People with high level of openness are creative, have a lively imagination, are curious, unconventional, and independent thinkers. Alternatively, people with low levels of openness tend to be more rigid, conventional and tend to follow rules and rely on habits. 
Agreeableness relates to the nature of individuals' relationships with other people; a person with a high level of agreeableness is friendly and empathic, gentle, likes to work with people, knows how to forgive and is understandable. Conscientiousness relates to level of accuracy, reliability, responsibility and persistence that is typical for a person. It is closely related to performance at work (Judge et al. 1999).

\section{Extraversion and Flow at Work}

Relation between flow and extraversion was confirmed by Bassi et al. (2013). A study on a sample of adolescents found that adolescents who achieve higher scores on the extraversion scale experience more flow and experience is more intense in schoolwork such as problem solving, finding the best solutions, etc.

\section{Neuroticism and Flow at Work}

One's state of flow can only occur if one's abilities are high enough to reach the goal. Flow cannot be experienced by a person who is overly phlegmatic and apathetic, nor by an individual who is frustrated and anxious (Culbertson et al. 2014).

People who predominately experience a positive affect have increased flexibility and creativity in how they face challenges. People with low emotional stability experience more negative effect, which means they are less likely to experience flow in comparison to people with predominant positive affect (Judge et al. 1999).

A neurotic personality trait is characterized by psychological discomfort, which is an emotional state that impedes the experience of flow. High levels of self-criticism and sense of vulnerability of individuals with low levels of emotional stability are expected to affect achievement and perception about one's own abilities, as well as the cognitive and affective experiences that are elements of flow (Mesurado and Richaud de Minzi 2012). Culbertson et al. (2014) also found a negative correlation between anxiety and job satisfaction in the study and concluded that an anxious person is not capable of experiencing flow.

\section{Openness and Flow at Work}

The connection between openness and flow has not been supported yet. We conclude that at the moment, there is no research showing an association between the personality dimension of openness and flow at work. 


\section{Agreeableness and Flow at Work}

Ross and Keiser (2014) state agreeableness is negatively related to experiencing a state of flow due to high levels of modesty in individuals who are high in agreeableness. Alternatively, agreeableness and flow have been positively correlated in a study by Bassi et al. (2013). Chu et al. (2013) could not find support that agreeableness mediates flow experience and job performance.

\section{Conscientiousness and Flow at Work}

It is likely that high levels of conscientiousness involve emotional and motivational mechanisms that encourage one to experience a state of flow. Individuals with high levels of conscientiousness are more dedicated to their work and more persistent. Bakker, Demerouti, and Brummelhuis (2012) examined the link between experiencing flow at work and job performance. They found that flow at work was a predictor of better work performance for employees with a high level of conscientiousness. Furthermore, Chu et al. (2013) found that conscientiousness trait mediates between flow experience and job performance.

\section{HYPOTHESES}

Based on the literature review the following hypotheses $(\mathrm{H})$ were formed:

H1 Flow at work and job satisfaction are positively correlated.

The core of motivational characteristics of work are the diversity of tasks, characteristics of work, autonomy, and receiving feedback (Demerouti 2006). These factors have also been proven to be predictors of job satisfaction. Although work satisfaction is a broader construct compared to flow, the factors contributing to the two are similar, so we concluded they are related (Demerouti 2006). We claimed that individuals who are satisfied with their work are more likely to experience flow at work (Straume 2004).

H2 Extraversion is positively correlated to flow at work.

Relation between flow and extraversion was confirmed by Bassi et al. (2013). A study on a sample of adolescents found that adolescents who achieve higher scores on the extraversion scale experience more flow. The link between extraversion and flow at work has also been empirically confirmed by Bassi et al. (2013). In addition, $\mathrm{Chu}$ et al. (2013) found extraversion trait mediates between flow experience and job performance.

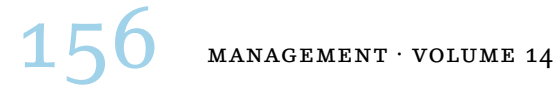


H3 Low emotional stability is negatively correlated to flow at work.

According to Culbertson et al. (2014) flow is unlikely to be experienced by individuals who are frustrated and anxious. We claim that neuroticism, through negative effect, is negatively correlated to flow at work. People with low emotional stability experience more negative effect, which means that they do not experience as much flow as people with predominant positive affect (Judge et al. 1999). High levels of self-criticism and sense of vulnerability of individuals with low levels of emotional stability are expected to affect perception about one's own abilities, as well as the cognitive and affective experiences that are elements of flow (Mesurado and Richaud de Minzi, 2012).

H4 Conscientiousness is positively correlated to flow at work.

Research focusing on examining the relationship between the personal dimension of conscientiousness and flow at work leads to the conclusion that these constructs are positively correlated (Bassi et al. 2013; Demerouti 2006). Individuals with high levels of conscientiousness are more dedicated to their work and more persistent. Bakker, Demerouti, and Brummelhuis (2012) examined the link between experiencing flow at work and job performance. They found that flow at work was a predictor of better work performance for employees with a high level of conscientiousness. Furthermore, Chu et al. (2013) found that conscientiousness trait mediates between flow experience and job performance.

\section{Methods}

In the following sections sample is presented. In addition, materials and procedure in the study are described.

\section{SAMPLE}

Primary school teachers of 450 Slovenian schools were invited to participate, with a total of 17,928 teachers at Slovenian elementary schools (Statistical Office of the Republic of Slovenia 2019). Nonprobability, convenience sample was used, since only those individuals whom survey was transferred by administration were able to participate (Blum and Goodman 1996). A total of 989 participants participated in the survey, but 99 of them did not complete the questionnaire, so they were eliminated. From 890 participants remaining, 810 were female and 80 were male. The age of the participants ranged from 25 to 60 years and they were all employed at Slovenian elementary schools. 
TABLE 1 Descriptive Statistics of the Questionnaire Topics

\begin{tabular}{llrrrrr}
\hline Construct & & $(1)$ & $(2)$ & $(3)$ & $(4)$ & $(5)$ \\
\hline Big five & Extraversion & 890 & 2.00 & 10.00 & 7.40 & 1.63 \\
& Nevroticism & 890 & 2.00 & 10.00 & 5.19 & 1.49 \\
& Agreeableness & 890 & 3.00 & 10.00 & 7.78 & 1.17 \\
& Conscientiousness & 890 & 4.00 & 10.00 & 8.33 & 1.27 \\
& Openess & 890 & 2.00 & 10.00 & 7.13 & 1.64 \\
\hline Flow at Work & & 890 & 4.00 & 20.00 & 15.36 & 2.31 \\
Bias & & 890 & 28.00 & 85.00 & 62.39 & 7.78 \\
\hline
\end{tabular}

Notes Column headings are as follows: (1) numerus, (2) minimum, (3) maximum, (4) arithmetic mean, (5) standard deviation.

\section{Materials and Procedure}

A questionnaire was compiled from three constructs: job satisfaction, flow and personality (The Big Five model). The questionnaire included four job satisfaction questions, which were adapted from The Brief Index of Affective Job Satisfaction (BIAJs) by Thompson and Phua (2012). 17 questions were applied to check flow at work (FLOW at Work; Jackson and Marsh 1996). Personality traits were examined with 10 questions based on the article by Rammstedt and John (2007). The questionnaire was applied in Slovene language. All questions were presented to the participants in the form of a 5-point scale, where 1 meant 'I disagree' and 5 'strongly agree.' Questionnaire was transformed into e-form and sent to administrators of Slovenian public schools. After receiving the questionnaires, those with missing values were removed from the sample. For analysis purposes, spss program was applied.

\section{Results}

First, descriptive statistics of the instruments used in the research is presented.

Table 1 shows that minimum and maximum scores in all three parts of questionnaire as well as average scores and standard deviations. It can be seen that regarding to personality the lowest average score was obtained in neuroticism and the highest average score in conscientiousness.

\section{RELIABILITY AND NORMALITY OF DISTRIBUTION \\ OF THE INSTRUMENTS}

Next, reliability measures (Cronbach's alpha) and normality of distribution are presented (Kolmogorov-Smirnov test). 
TABLE 2 Reliability and Normality of Distribution of the Instruments

\begin{tabular}{llrr}
\hline Questionnaire & & (1) & $(2)$ \\
\hline 10-Item Personality Scale & Extraversion & 0.634 & 0.000 \\
& Neuroticism & 0.525 & 0.000 \\
& Agreeableness & 0.783 & 0.000 \\
& Conscientiousness & 0.429 & 0.000 \\
& Openess & 0.530 & 0.000 \\
\hline Flow-W questionnaire & & 0.882 & 0.000 \\
Brief index of affective job satisfaction & 0.817 & 0.000 \\
\hline
\end{tabular}

NOTES Column headings are as follows: (1) $\alpha$ coefficient, (2) normality of distribution.

The reliability of the instruments used varies, ranging from 0.429 to 0.882 . All subscales of the Big Five questionnaire proved to be less reliable, conscientiousness $(\alpha=0.429)$ is the least reliable of all. For improvement, spss program offered us the opportunity to remove one of the questions on all personality subdimensions, but this would mean that each personality trait would be represented by only one question, so we decided to leave the questionnaire in its original form. The most reliable was FLow-w questionnaire ( $\alpha=$ 0,882 ). For all instruments, a distribution that deviates significantly from the normal distribution was found. Because of this, we decided to use the Spearman correlation tests in order to test hypotheses.

\section{THE RELATIONSHIP BETWEEN JOB SATISFACTION \\ AND FLOW AT WORK}

$\mathrm{H} 1$ assumed job satisfaction and flow at work were positively correlated. The correlation coefficient is 0.671 and it ranges between 0.3 and 0.69 , which means that work-related job satisfaction and flow at work are moderately positively correlated.

THE RELATIONSHIP BETWEEN EXTRAVERSION

AND FLOW AT WORK

H2 assumed extraversion and flow at work were positively correlated. The correlation coefficient is 0.221 and it ranges from 0.1 to 0.29 , so we conclude that extraversion is weakly positively correlated to flow at work.

THE RELATIONSHIP BETWEEN NEUROTICISM AND FLOW AT WORK H3 proposed conscientiousness and flow at work were negatively correlated. The correlation coefficient is -0.270 and it ranges be- 
tween -0.29 and -0.1, so we conclude that neuroticism is weakly negatively correlated with flow at work.

THE RELATIONSHIP BETWEEN CONSCIENTIOUSNESS

AND FLOW AT WORK

H4 assumed positive relationship between conscientiousness and flow at work. The correlation coefficient (0.366) shows conscientiousness is moderately positively related to flow at work.

\section{Conclusions}

In this study, we examined how flow at work is related to job satisfaction. Furthermore, we were interested in relationship between flow at work and three dimensions of the Big Five model (namely extraversion, neuroticism and conscientiousness).

Results show that flow at work and job satisfaction are positively correlated ( $\mathrm{H} 1)$. The results are consistent with those of Demerouti (2006), who concluded that the factors contributing to the two constructs are similar. High intrinsic motivation encourages both experiencing the flow at work and the fact that the individual is satisfied with his or her work. The results are also consistent with Straume (2004), who demonstrated a positive correlation between flow at work and job satisfaction. Thus, more satisfied teachers are more likely to experience flow at work.

Additionally, a weak positive association between extraversion and flow at work was found. The results are consistent with the findings reported by Bassi et al. (2013) in their research. Thus, we can confirm н2.

Flow at work and neuroticism were negatively correlated. Thus, a person with a higher level of emotional stability is more likely to experience flow at work than a person with a lower level of emotional stability. This is in line with the findings of several studies that find that neuroticism and flow at work are negatively correlated. The results of this study match the studies of Birch and Kamali (2001) and Culbertson et al. (2014), who found that a person who is prone to anxiety experiences a lesser degree of flow at work. H3 has thus been confirmed.

H4 was confirmed as well. It was found that there was a moderate positive correlation between flow at work and conscientiousness. The findings are in line with the results of Bassi et al. (2013), who found that conscientiousness encompasses personality traits associated with promoting work-related passion such as dedication and perseverance, participation in difficult challenges, constructive 
problem solving, job satisfaction, and internal and external motivation. It is likely that if an individual has a highly expressed personality dimension of conscientiousness, he or she is more intrinsically motivated, which in turn promotes experiencing a state of flow. In addition, our results are consistent with Demerouti (2006) and Bakker, Demerouti, and Brummelhuis (2012) who showed that people with higher degrees of conscientiousness are more successful at work and, as a result, experience flow repeatedly.

We also tested the relationship between flow at work and openness. A weak correlation between the two constructs was found, thus showing a possibility of further investigation of the relationship. We also found a weak positive correlation between agreeableness and flow at work. Previous research was not unified on whether a relation between flow and agreeableness is positive or negative.

It is important for leaders to realise that well-being at work is connected to personality traits, so employees with certain personality structures are more likely to experience job satisfaction and flow at work. Hence, principals should pay more attention to HRM practices (namely human resourse selection and retention practices). Furthermore, it is important to monitor job satisfaction and flow at work in primary schools and make possible changes in the way teachers work and socialise.

Furthermore, principals in Slovenian public primary schools are in charge of creating a positive atmosphere in order for the teachers to experience high levels of job satisfaction. Semi-official and in-official gatherings (such as sport or cultural events, celebrations, trips) organised for the teachers as well as annual interviews with teachers can improve teachers' work attitudes as well as (indirectly) flow at work. Further research in this area should primarily improve the reliability of the Big Five model questionnaire. It is imperative that the personality questionnaire is expanded and improved. It would also be necessary to change the method of sampling in order to get more reliable results and to be able to generalize results to the entire population of Slovenian primary school teachers.

\section{References}

Bakker, A. B., E. Demerouti, and L. L. Brummelhuis. 2012. 'Work Engagement, Performance, and Active Learning: The Role of Conscientiousness.' Journal of Vocational Behavior 80 (2): 555-64.

Bassi, M., and A. Delle Fave. 2012. 'Optimal Experience among Teachers: New Insights into the Work Paradox.' The Journal of Psychology 146 (5): 533-57. 
Bassi, M., P. Steca, D. Monzani, A. Greco, and A. Delle Fave. 2013. 'Personality and Optimal Experience in Adolescence: Implications for Well-Being and Development.' Journal of Happiness Studies 15 (4): 829-43.

Blum, T. C., and J. S. Goodman. 1996. 'Assessing the Non-Random Sampling Effects of Subject Attrition in Longitudinal Research.' Journal of Management 22 (4): 627-52.

Branković, E., M. Hadžikadunić, and M. Mijanović. 2017. 'Intrinsic Motivation and Autotelic Activity in Students.' Kinesiologia Slovenica 23 (1): $14^{-24}$.

Csikszentmihaly, M. 2014. Flow and the Foundations of Positive Psychology: The Collected Works of Mihaly Csikszentmihaly. New York: Springer.

Culbertson, S. S., C. J. Fullagar, M. J. Simmons, and M. Zhu. 2014. 'Contagious Flow: Antecedents and Consequences of Optimal Experience in the Classroom.' Journal of Management Education 39 (3): 319-49.

Debus, M. E., W. Deutsch, S. Sonnentag, and F. W. Nussbeck. 2014. 'Making Flow Happen: The Effects of Being Recovered on Work-Related Flow Between and Within Days.' Journal of Applied Psychology 99 (4): 719-22.

Delle Fave, A., and F. Massimini. 2005. 'The Investigation of Optimal Experience and Apathy.' European Psychologist 10 (4): 264-74.

Demerouti, E. 2006. 'Job Characteristics, Flow, and Performance: The Moderating Role of Conscientiousness.' Journal of Occupational Health Psychology 11 (3): 266-80.

Dimec, T., J. Mahnič, M. Marinšek, R. Masten, and M. Tušak. 2008. 'Zadovoljstvo z življenjem in delovno zadovoljstvo zaposlenih $\mathrm{V}$ Slovenski vojski.' Psihološka obzorja 17 (4): 117-30.

Fullagar, C., A. Delle Fave, and S. Van Krevelen. 2017. 'The Evolution of a Construct.' In Flow at Work: Measurement and Implication, edited by C. Fullagar and A. Delle Fave, 1-28. New York: Routledge.

Judge, T. A., C. A. Higgins, C. J. Thoresen, and M. R. Barrick. 1999. 'The Big Five Personality Traits, General Mental Ability, and Career Success Across the Life Span.' Personnel Psychology 52 (3): 621-45.

Judge, T. A., and R. Klinger. 2008. 'Job Satisfaction: Subjective WellBeing at Work.' In The Science of Subjective Well-Being, edited by M. Eid and R. J. Larsen, 393-413. The Guilford Press: New York.

Kopperud, K. H. and L. V. Straume. 2009. 'Flow - A Positive Experience.' In Validation and Test of Central Concepts in Positive Work and Organizational Psychology, edited by M. Christensen, 30-39. Copenhagen: TemaNord.

Chu, L.-C., C.-L. Lee, K.-C. Huang, and J.-H. Lin. 2013. 'How Personality Traits Mediate the Relationship Between Flow Experience and Job Performance.' The Journal of International Management Studies 8 (1): 33-46. 
Mesurado, B., and M. C. Richaud de Minzi. 2012. 'Child's Personality and Perception of Parental Relationship as Correlates of Optimal Experience.' Journal of Happiness Studies 14 (1): 199-214.

Nakamura, J., and M. H. Csikszentmihaly. 2005. 'The Concept of Flow.' In Handbook of Positive Psychology, edited by C. R. Snyder and S. J. Lopez, 89-103. New York: Oxford University Press.

Ross, S. R., and H. N. Keiser. 2014. 'Autotelic Personality through a FiveFactor Lens: Individual Differences in Flow-Propensity.' Personality and Individual Differences 59:3-8.

Seemann, M., and T. Seemann. 2015. 'New Perspectives on Employee Motivation: Balancing the Big Four.' The International Journal of Knowledge, Culture, and Change in Organizations 13 (1): 1-7.

Smolej Fritz, B., and A. Avsec. 2007. 'The Experience of Flow and Subjective Well-Being of Music Students.' Psihološka obzorja 16 (2): 517.

Statistical Office of the Republic of Slovenia. 2019. 'Z vsakim šolskim letom več učitelje: odstotek moških med pedagoškimi delavci se dviga s stopnjami izobraževanja.' https://www.stat.si/statweb/News/ Index/7700

Straume, L. V. 2004. Flow as a Resource: A Contribution to Organizational Psychology. Trondheim: Tapir Akademisk Forlag.

Van Dongen, H. P. A., and D. F. Dinges. 2000. 'Circadian Rhythms in Fatigue, Alertness and Performance.' In Principles and Practice of Sleep Medicine, edited by M. H. Kryger, T. Roth, and W. C. Dement 391-99. Philadelphia: Saunders. 